\title{
A qualidade das informações sobre doenças disponíveis em websites brasileiros: uma revisão
}

\author{
Quality of the information about diseases available in Brazilian websites: a review
}

Guilherme Malafaia', André Luis da Silva Castro', Aline Sueli de Lima Rodrigues'

\begin{abstract}
Resumo
Este estudo, por meio de uma revisão da literatura, teve o propósito de alertar para a possibilidade de obtenção de informações incorretas veiculadas na internet sobre doenças. Durante a revisão, buscou-se por trabalhos que avaliaram a qualidade das informações sobre doenças divulgadas por websites do Brasil. A consulta dos artigos deu-se por meio dos bancos de dados LILACS - BIREME, MEDLINE, SciELO e PubMed, sendo que o recorte temporal foi de 2000 a 2009. Verificou-se que poucos foram os estudos que avaliaram a qualidade das informações sobre doenças disponíveis na internet, sendo que os encontrados versam sobre a rinite alérgica, leishmaniose visceral e tegumentar, doença de Chagas (tripanossomíase americana) e obesidade. Os resultados obtidos também demonstram que, em geral, as informações divulgadas nos websites analisados são incorretas, incompletas, desatualizadas e pobres em embasamento científico. Portanto, alerta-se para o perigo de obtenção de informações incorretas sobre doenças e sugere-se a criação de mecanismos de disseminação de informações corretas sobre as enfermidades, na internet, aproveitando esta ferramenta útil para a prevenção e 0 controle das mais variadas doenças no Brasil.
\end{abstract}

Palavras-chave: internet; comunicação e divulgação científica; doença.

\section{Abstract}

This study, through a review, aimed to alert to the possibility of getting incorrect information available on the internet about diseases. During the review, we sought by studies that evaluated the quality of information about diseases, available on Brazilians websites. The consultation of papers occurred through LILACS - BIREME, MEDLINE, PubMed and SciELO databases, and the time frame was 2000 to 2009 . Few studies have evaluated the quality of information about disease available on the internet, and those found dealed with allergic rhinitis, cutaneous and visceral leishmaniasis, Chagas disease (American trypanosomiasis) and obesity. The results also show that, in general, the information disseminated on the websites analyzed are inaccurate, incomplete, outdated and poor in scientific basis. Therefore, this study alerts to the danger of getting incorrect information about diseases and suggests the creation of mechanisms to disseminate correct information about the diseases, on the internet, taking advantage of this useful tool for the prevention and control of many different diseases in Brazil.

Keywords: internet; scientific communication and diffusion; disease.

Recebido em: 26/9/2010

Revisado em: 11/2/2011

Aprovado em: 15/3/2011

\footnotetext{
Trabalho realizado no Instituto Federal Goiano - Campus Urutaí - Urutaí (GO), Brasil.

Núcleo de Pesquisa em Ciências Ambientais e Biológicas do Instituto Federal Goiano - Urutaí, (GO), Brasil.

Endereço para correspondência: Guilherme Malafaia - Instituto Federal Goiano, Campus Urutaí - Rodovia Geraldo Silva Nascimento, km 2,5 - Zona

Rural - CEP: 75790-000 - Urutaí (GO), Brasil - E-mail: guilhermebioufop@yahoo.com.br
} 


\section{Introdução}

Atualmente, devido ao aumento do acesso à rede mundial de computadores (internet) e às inúmeras discussões promovidas pelos órgãos de comunicação social, tem sido observada uma crescente divulgação de informações de saúde. Conforme discutido por Santana e Pereira ${ }^{1}$, o aumento do uso da internet e do seu emprego para questões de saúde tem sido assunto de merecido destaque na atualidade. Concomitantemente, verificam-se também a expansão de programas de autoajuda e de ajuda mútua, centrados no paciente, além do crescimento de um consumismo associado ao tema da saúde, o aumento do ativismo e da organização dos pacientes e a afirmação de medicinas complementares e alternativas, todos estes podendo ser vinculados e disseminados diretamente pela internet.

No Brasil, assim como em outros países, a internet inicialmente interligava laboratórios de pesquisa e estava vinculada à área acadêmica e militar, expandindo-se comercialmente a partir de 1994². Em 2003, o Brasil tinha apenas 7,3 milhões de usuários de internet domiciliares ativos, tendo atingido 18,6 milhões de usuários em 2004, dos quais 11,6 milhões eram considerados usuários ativos ${ }^{3}$. Atualmente, dados recentes de uma pesquisa encomendada pela seguradora britânica Bupa Health Pulse revelam que 86\% dos brasileiros com acesso à internet já buscaram orientações sobre saúde 4 .

Os trabalhos de Cuenca e Tanaka ${ }^{5}$ de e Castro ${ }^{6}$ mostram que a internet tem facilitado a divulgação da informação científica entre os profissionais da área da saúde de diversas maneiras, proporcionando pesquisas bibliográficas gratuitas, veiculando o conteúdo de periódicos de várias especialidades, facilitando a aquisição de equipamentos médicos e materiais didáticos, bem como promovendo o intercâmbio de informações por meio de grupos de discussão, videoconferências, além de outras contribuições valorosas ao meio médico. Da mesma forma, os benefícios da internet podem ser extrapolados ao público leigo. Qualquer pessoa que tenha acesso à rede - desconsiderando as amplas diferenças entre as classes socioeconômicas que realmente têm acesso à internet e também a elitização no público que acessa a web no Brasil - pode facilmente receber orientações sobre prevenção, diagnóstico e tratamento de doenças ${ }^{7}$, fato este que auxilia os usuários e complementa as informações dadas pelo profissional da área médica. Dos 63 milhões de pessoas que acessaram a internet no Brasil, no ano de 2009, o número de pessoas que buscou informações sobre saúde cresceu expressivamente, representando 39\% dos internautas, o que significa uma diferença de 6\% em comparação com o ano de 2008, segundo o Centro de Estudos sobre as Tecnologias da Informação e da Comunicação ${ }^{8}$.
No entanto, pode-se dizer que as informações sobre doenças disponíveis internet são verídicas, de boa qualidade ${ }^{1}$ e, consequentemente, confiáveis? Esta é uma pergunta que tem merecido grande atenção, uma vez constatado que pacientes procuram, cada dia mais, por informações online sobre saúde e consultam menos os médicos, como pode ser observado, por exemplo, no estudo de Richard et al. ${ }^{9}$. Contudo, a adequação e a qualidade das informações sobre doenças veiculadas pela internet são questionáveis, o que torna a questão preocupante, uma vez que o conteúdo incorreto sobre uma determinada doença pode favorecer sua proliferação ou agravar o seu quadro clínico. Além disso, em muitas situações, o paciente pode realizar a automedicação, após consultar informações na internet. Conforme relatado nos estudos de Weisbord et al. ${ }^{10}$ e Hainer et al. ${ }^{11}$, por exemplo, os pacientes podem, inclusive, evoluir para óbito, quando utilizam medicações prescritas em páginas da internet, sem fundamentação científica e acompanhamento médico especializado.

Neste contexto, o presente estudo teve como objetivo apresentar nesta revisão da literatura os estudos que se dispuseram avaliar a qualidade das informações sobre algumas doenças, disponíveis em websites brasileiros, bem como discutir a importância da qualidade das informações acerca das enfermidades, veiculadas na internet. Pretende-se, com este estudo, oferecer subsídios que podem ajudar na superação dos desafios pertinentes à divulgação de informações sobre doenças, disponíveis na internet.

\section{Métodos}

Para a realização deste estudo, foram selecionados os trabalhos que abordaram os principais aspectos relacionados à divulgação do conteúdo científico, à disponibilização de informações sobre doenças na internet, aos critérios de avaliação da qualidade da informação em saúde recuperadas na internet e, especificamente, aos estudos que analisaram as informações sobre doenças, disponíveis em websites brasileiros.

Para a busca dos artigos científicos, os bancos de dados LILACS - BIREME (base de dados da literatura Latino Americana e do Caribe em Ciência da Saúde), MEDLINE - Index Medicus (Medical Literature Analysis and Retrieval System Online), SciELO (Scientific Eletronic Library Online) e PubMed (mantido pela National Library of Medicine) foram consultados. Os seguintes descritores de pesquisa (palavraschave e/ou delimitadores), escritos em português e em inglês, foram utilizados em várias combinações: i) "internet"; ii) "doenças"; iii) "divulgação científica"; iv) "comunicação"; v) "websites"; vi) "informações"; vii) "portais brasileiros" e viii) "Brasil".

O recorte temporal abrangeu o período compreendido entre os anos de 2000 e 2009, sendo considerados os seguintes critérios para a se-

\footnotetext{
1 A questão da qualidade da informação, em qualquer meio, apresenta natureza muito subjetiva, além de haver também uma grande dificuldade em definir o próprio conceito de qualidade da informação. Na internet, muito mais do que em outros meios, a definição do que venha ser uma informação de boa qualidade fica muito mais a critério do usuário do que do produtor/autor/responsável da/pela informação, por exemplo. Entretanto, existem alguns fatores que podem ajudar a definir, em parte, um conteúdo que tenha qualidade. São eles: a necessidade de informação existente; neste caso, a informação deve ser capaz de reduzir a incerteza que se tem; a cobertura; periodicidade de atualização; autoria do conteúdo divulgado; a veracidade e completeza da informação e fundamentação científica, entre outros.
} 
leção: i) artigos que tratassem especificamente da análise da adequação e da qualidade das informações sobre doenças, veiculadas em websites brasileiros; ii) artigos que tratassem dos critérios da qualidade da informação em saúde e/ou doença, disponível na internet; iii) artigos que tratassem da importância da internet no que diz respeito à disseminação do conhecimento científico; iv) procedência e idioma: artigos nacionais e internacionais publicados em revistas especializadas e v) tipo de publicação: periódicos.

\section{Resultados e discussão}

\section{Estudos sobre a qualidade das informações sobre doenças disponíveis, em websites brasileiros}

Conforme discutido por Silva et al. ${ }^{12}$, dada a facilidade de se obterem informações veiculadas pela internet, o público leigo pode facilmente receber orientações sobre prevenção, diagnóstico e tratamento de diversas doenças, o que os auxilia a complementar as informações dadas pelo médico, ou simplesmente os estimulam a tomar decisões individuais frente a um processo patológico, por exemplo, sem o conhecimento de um médico especializado. Esta constatação toma proporções ainda maiores quando se considera que nem sempre a qualidade das informações sobre as doenças, veiculadas em websites, é de boa qualidade e correta.

Após a realização da busca por trabalhos que trataram especificamente de analisar a adequação e a qualidade das informações sobre doenças, disponíveis em websites brasileiros, poucos estudos foram encontrados (Tabela 1).

Em pesquisa realizada no início dos anos 2000, Balbani et al. ${ }^{13}$ avaliaram as informações disponíveis na internet, em língua portuguesa, sobre rinite alérgica e rinossinusite/sinusite. Conforme estimado por $\mathrm{Castro}^{14}$, a rinite alérgica pode atingir cerca de 10 a $20 \%$ da população mundial e mais de 15 a $25 \%$ das crianças e adolescentes.

$\mathrm{Na}$ ocasião, foram consultadas páginas da rede escolhidas aleatoriamente dentre as listadas por mecanismos de busca (AltaVista, Yahoo!, Radix, Cadê?, America OnLine), totalizando amostras de 50 páginas sobre rinite alérgica e 125 sobre rinossinusite/sinusite. Os autores levaram em consideração para as análises dos websites as seguintes variáveis: i) a instituição/pessoa responsável pela sua veiculação das informações e ii) a adequação do conteúdo acerca da rinite alérgica e rinossinusite/sinusite, disponível em cada website. Quanto à avaliação do conteúdo, verificou-se a i) exatidão das informações científicas, tomando-se por base a literatura médica, bem como as ii) características gerais dos websites, incluindo as informações disponíveis voltadas para a classe médica e para leigos.

Os resultados do estudo de Balbani et al. ${ }^{13}$ demonstraram que, em geral, as informações de caráter científico sobre rinite alérgica e rinossinusite/sinusite disponíveis na internet foram consideradas pobres em conteúdo. Além disso, sobre a rinite alérgica, verificou-se que 13,6\% dos websites analisados continham dados errôneos sobre a doença e, em $14 \%$ deles, não se conseguiu identificar o autor ou entidade responsável pelas informações. Já sobre a rinossinusite, os autores verificaram que, embora a maioria dos websites analisados contivesse informações básicas corretas, algumas vezes as informações estavam desatualizadas ou em linguagem de difícil compreensão por pessoas não especializadas, já que continham jargões e termos técnico-científicos usados mais comumente entre os profissionais da área de saúde.

Em estudo mais recente, Silva et al..$^{12}$ também avaliaram as informações sobre rinite alérgica, disponíveis em websites brasileiros, bem como os princípios éticos destes websites, pois além da responsabilidade de oferecer conteúdo fidedigno, correto e de qualidade, os indivíduos e/ou organizações responsáveis pela criação e manutenção de websites relacionados à saúde das pessoas devem também proteger a privacidade dos cidadãos e respeitar as normas regulamentadoras do exercício ético profissional da Medicina. Silva et al. ${ }^{12}$ promoveram a busca dos websites a serem analisados por meio dos seguintes motores de busca: Google, AltaVista, Yahoo! e Radar UOL. Para a análise da exatidão das informações sobre rinite alérgica, os autores utilizaram a literatura especializada e, para a avaliação dos princípios éticos seguidos por cada website visitado e analisado, tomaram como base o Manual de Princípios Éticos para Sites de Medicina e Saúde do Conselho Regional de Medicina do Estado de São Paulo (CREMESP).

Pode-se considerar que os resultados obtidos foram surpreendentes. Entre os websites analisados (um total de 173), 86,1\% não estavam de acordo com o Manual de Princípios Éticos para Sites de Medicina e Saúde do CREMESP. Foram encontradas irregularidades nos websites, de acordo com os itens avaliados, nas seguintes proporções: qualida-

Tabela 1: Estudos que analisaram a qualidade de informações sobre doenças, disponíveis em websites brasileiros

\begin{tabular}{lccc}
\hline Referências bibliográficas & Doença estudada & Número de websites analisados & Motores de busca utilizados na seleção dos websites \\
\hline Balbani et al. $^{13}$ & Rinite alérgica & 50 & AltaVista \\
Silva et al. ${ }^{12}$ & Rinossinusite/sinusite & 125 & AltaVista, Yahoo!, Radix, Cadê? e America OnLine \\
Souza et al. ${ }^{15}$ & Rinite alérgica & $173^{*}$ & Google, Alta Vista, Yahoo e Radar UOL \\
Silva et al. ${ }^{16}$ & Leishmaniose visceral & $24^{*}$ & Google \\
Malafaia $^{7}$ & Obesidade & $100^{*}$ & Google \\
Malafaia e Rodrigues $^{17}$ & Doença de Chagas & $37^{*}$ & Google \\
\hline
\end{tabular}

*Vale salientar que os websites analisados foram aqueles de caráter informativo, ou seja, aqueles que apresentaram objetivo explícito de divulgar informações sobre as doenças e/ou aqueles que, dentre outras finalidades, também continham informações sobre as enfermidades. 
de $(84,4 \%)$, privacidade $(46,2 \%)$ honestidade $(18,5 \%)$, consentimento livre e esclarecido (15,6\%), responsabilidade (13,9\%), transparência $(12,1 \%)$ e ética médica (2,3\%). Além disso, foi constatado que havia informações inexatas em 24,3\% dos websites analisados. No Quadro 1, é possível observar um sumário dos princípios éticos conceituados pelo CREMESP que nortearam a avaliação realizada por Silva et al. ${ }^{12}$.

Outro estudo encontrado na presente pesquisa refere-se ao trabalho de Souza et al..$^{15}$, no qual foi analisada a adequação da informação sobre leishmaniose visceral (LV), disponível em websites brasileiros. Na ocasião, os autores realizaram o levantamento de websites por meio do portal de busca Google, sendo que 24 foram selecionados para análise. Informações sobre a transmissão, reservatório, controle/profilaxia, bem como sobre os aspectos clínicos e terapêuticos da doença foram investigadas. Os resultados obtidos evidenciam a elevada frequência de informações ausentes em relação a todos os tópicos pesquisados, e em todos os websites analisados. Observou-se que mais de $50 \%$ dos websites governamentais e mais de $60 \%$ dos não-governamentais não apresentavam informações sobre a profilaxia, sintomatologia e/ou tratamento da doença. Além disso, muitas páginas apresentaram conteúdo incorreto sobre a LV. Apenas como exemplo, cita-se o trecho a seguir (extraído de um website analisado), o qual apresenta um conteúdo equivocado, que pode, inclusive, influenciar as práticas dos internautas relativas às suas contribuições para o controle da LV: "Pessoas infectadas com o parasita, devem ser obrigatoriamente isoladas em local apropriado, a fim de ser impedido serem sugadas pelos vetores Flebótomos, interrompendo a cadeia evolutiva do protozoário.
Trata-se, no entanto, de uma doença chamada exótica, felizmente presente em pouquíssimos locais do território Brasileiro. Por essas características, quando diagnosticado um foco da doença, fazem-se necessárias medidas enérgicas para sua erradicação, sob pena de sua disseminação" 15 .

Em outro estudo, Silva et al. ${ }^{16}$ avaliaram a forma como as informações sobre o tratamento farmacológico da obesidade são apresentadas em websites brasileiros, considerando o potencial da internet de disseminar informação errônea sobre esse tema e a relevância do problema. Sabe-se que a obesidade é uma doença que está alcançando níveis epidêmicos. Nesse estudo, a seleção dos websites para avaliação ocorreu por meio da ferramenta de busca Google, no modo "Pesquisa avançada”, opção “páginas em português” e país “Brasil”, realizando-se quatro pesquisas independentes com os seguintes descritores: "obesidade" e "tratamento"; "emagrecimento" e "tratamento"; "perda de peso" e "anorexígenos". Após a aplicação dos critérios de exclusão, um total de 100 páginas foi analisado. Os resultados revelaram baixa frequência de informações sobre a autoria, data de elaboração do conteúdo e listagem de referências, o que compromete a qualidade da informação divulgada e requer cautela na utilização das páginas consultadas para a busca de informações sobre o tratamento farmacológico da obesidade.

Seguindo essa mesma linha de pesquisa, destaca-se o recente estudo de Malafaia ${ }^{7}$, que avaliou o conteúdo das informações sobre a doença de Chagas (também conhecida como tripanossomíase americana), divulgadas em websites brasileiros, bem como a qualidade do conteúdo das informações neles disponíveis. Nesse estudo, foi selecionado um total

Quadro 1: Sumário conceitual dos princípios éticos estabelecidos pelo Conselho Regional de Medicina do Estado de São Paulo (CREMESP)

\begin{tabular}{|c|c|}
\hline Critério & Descrição \\
\hline Transparência & $\begin{array}{l}\text { Toda informação que possa interferir na compreensão das mensagens veiculadas ou no consumo dos serviços e produtos ofer- } \\
\text { ecidos por websites com conteúdo de saúde e medicina deve ser transparente e pública. É necessário estar claro se o website é } \\
\text { apenas educativo ou se tem fins comerciais na venda de espaço publicitário, produtos, serviços, atenção médica personalizada, } \\
\text { assessoria ou aconselhamento. É obrigatória a apresentação dos nomes do responsável, mantenedor e patrocinadores diretos ou } \\
\text { indiretos dos websites. }\end{array}$ \\
\hline Honestidade & $\begin{array}{l}\text { As informações disponibilizadas pelos websites devem ser verdadeiras sem que haja interesses ocultos. Deve estar claro quando } \\
\text { o conteúdo educativo ou científico divulgado (afirmações sobre a eficácia, efeitos, impactos ou benefícios de produtos ou serviços } \\
\text { de saúde) tiver o objetivo de publicidade, promoção e venda, conforme Resolução CFM N }{ }^{0} 1.595 / 2000 \text {. }\end{array}$ \\
\hline Qualidade & $\begin{array}{l}\text { A informação divulgada na internet deve ser exata, atualizada, de fácil entendimento, em linguagem objetiva e cientificamente } \\
\text { fundamentada. Dicas e aconselhamentos em saúde devem ser prestados por profissionais qualificados, com base em estudos, } \\
\text { pesquisas, protocolos, consensos e prática clínica. Além disso, deve estar visível a data da publicação ou da revisão da infor- } \\
\text { mação, assim como as fontes utilizadas para as informações, critério de seleção de conteúdo e política editorial do website, com } \\
\text { destaque para nome e contato com os responsáveis. }\end{array}$ \\
\hline $\begin{array}{l}\text { Consentimento livre e } \\
\text { esclarecido }\end{array}$ & $\begin{array}{l}\text { Quaisquer dados pessoais somente podem ser solicitados, arquivados, usados e divulgados apenas com o expresso consentimento } \\
\text { livre e esclarecido dos usuários, que devem ter clareza sobre o pedido de informações. Os websites devem declarar se existem riscos } \\
\text { potenciais à privacidade da informação dos usuários, se existem arquivos para "espionagem" dos passos do internauta na rede, que } \\
\text { registra as páginas ou serviços que visitou, nome, endereço eletrônico, dados pessoais sobre saúde, compras online, etc. }\end{array}$ \\
\hline Privacidade & $\begin{array}{l}\text { Os websites devem deixar claros seus mecanismos de armazenamento e segurança para evitar o uso indevido de dados, por meio } \\
\text { de códigos, contra-senhas, softwares e certificados digitais de segurança, apropriados para todas as transações que envolvam } \\
\text { informações médicas ou financeiras pessoais do usuário. }\end{array}$ \\
\hline Ética médica & $\begin{array}{l}\text { Os profissionais médicos e instituições de saúde registradas no CREMESP que mantêm websites devem obedecer os mesmos } \\
\text { códigos e normas éticas regulamentadoras do exercício profissional convencional. Se a ação, omissão, conduta inadequada, im- } \\
\text { perícia, negligência ou imprudência de um médico, via internet, produzir dano à vida ou agravo à saúde do indivíduo, o profissional } \\
\text { responderá pela infração ética junto ao Conselho de Medicina e estará sujeito a penas disciplinares. }\end{array}$ \\
\hline $\begin{array}{l}\text { Responsabilidade e } \\
\text { procedência }\end{array}$ & $\begin{array}{l}\text { Alguém ou alguma instituição deve se responsabilizar, legal e eticamente, pelas informações, produtos e serviços de medicina } \\
\text { e saúde divulgadas na internet. Deve estar explícito aos usuários: quem são e como contatar os responsáveis pelo website e os } \\
\text { proprietários do domínio. Além disso, o website deve manter ferramentas que possibilitem ao usuário emitir opinião, queixa ou } \\
\text { dúvida. As respostas devem ser fornecidas da forma mais ágil e apropriadas possíveis. É obrigatória a identificação dos médicos } \\
\text { que atuam na internet, com nome e registro no Conselho Regional de Medicina. }\end{array}$ \\
\hline
\end{tabular}


de 37 websites, que, por meio de um formulário, tiveram seus conteúdos relativos a seis blocos de informações: transmissão/etiologia, reservatório, controle/profilaxia, doença, tratamento e epidemiologia. Apenas $8,3 \%$ dos websites analisados continham informações corretas e completas em relação aos blocos de informações mencionados anteriormente. Em $91,7 \%$ dos websites, foi observada pelo menos uma classificação "ausente" para os tópicos dos blocos de informações estabelecidos. Além disso, foi constatado um elevado percentual de websites que disponibilizaram informações equivocadas sobre a doença de Chagas. Ao difundir informações incorretas, tais como " $O$ parasita se reproduz no intestino do mosquito após passar de tripomastigoto para epimastigoto (...)" ou "O mosquito da vez éo Lutzomyia longigalpis, mais conhecido como Barbeiro" ou ainda, “(...) mal de chagas, é uma doença transmissivel causada por um protozoário parasita denominado Trypanosoma cruzi, popularmente conhecido por barbeiro, chupança, chupão, fincão, bicudo e procotó, dentre outros nomes"', tais websites transmitem informações equivocadas aos usuários. Como é sabido, os insetos vetores da doença de Chagas estão incluídos na ordem Hemiptera e não na ordem Diptera, na qual estão incluídas as moscas e mosquitos. Além disso, o mosquito Lutzomyia longipalpis é considerado uma espécie transmissora da LV e não da doença de Chagas, e os nomes populares "barbeiros", "chupança”, "fincão", "bicudo" e "procotó” são referidos aos vetores da doença de Chagas e não ao protozoário causador, conforme explícito em um dos websites analisados.

Dados preocupantes também foram observados no recente estudo de Malafaia e Rodrigues ${ }^{17}$, o qual objetivou analisar o conteúdo das informações sobre a leishmaniose tegumentar americana (LTA), disponível em websites brasileiros, bem como avaliar a qualidade dos websites visitados. Neste estudo, utilizando-se de uma metodologia semelhante à adotada no estudo de Souza et al. ${ }^{15}$, foi adotado, na pesquisa, um formulário composto por 28 tópicos agrupados em seis blocos de informações: "transmissão/etiologia”, "reservatório”, “doença/diagnóstico”, "tratamento", "epidemiologia” e "controle/profilaxia”. Já para a avaliação da qualidade dos websites visitados, foram utilizados os seguintes critérios: “exatidão", "atualização”, “autoria”, "fundamento científico", "linguagem" e "interação com o usuário". Corroborando estudos correlatos, Malafaia e Rodrigues ${ }^{17}$ concluíram que a maioria dos websites analisados, assim como as informações por eles disponibilizadas são de baixa qualidade, tendo sido observados elevados percentuais de ausência de informações referentes aos tópicos discriminados em cada um dos blocos de informações. Um percentual de $76,5 \%$ dos websites analisados apresentou informações desatualizadas sobre a doença, em mais da metade não estava explícito o(s) autor(es) ou o(s) responsável(is) pelas informações divulgadas e apenas $17,6 \%$ deixaram clara a origem das informações, expressa, por exemplo, por meio de uma lista de referências bibliográficas, carecendo, portanto, de fundamentação científica. Além disso, foram verificadas incorreções quanto à nomenclatura científica utilizada nos textos em, aproximadamente, $60 \%$ dos websites analisados e em $52,9 \%$ não foram encontradas ferramentas que possibilitassem aos usuários emitir opiniões e queixas ou ainda esclarecer dúvidas por meio de um link específico.
A partir da análise dos resultados apresentados acima, fica evidente e comprovada a existência de informações equivocadas sobre doenças disponíveis em websites brasileiros, fato este que incide diretamente na qualidade da informação sobre os mais variados aspectos dessas enfermidades. Além disso, pôde-se observar que muitos websites, ao disponibilizarem conteúdos descritivos sobre as doenças, acabam omitindo informações que não contribuem para o entendimento da doença e da sua complexidade. Pode-se dizer que a utilização de informações incorretas ou incompletas sobre doenças representa não apenas um potencial prejuízo à saúde do internauta, mas também significa a perda de oportunidade de utilização da internet como uma ferramenta útil no controle e prevenção de várias patologias que afligem a população.

\section{Considerações sobre os critérios de avaliação da qualidade das informações em saúde veiculadas pela internet}

É plausível afirmar que as publicações eletrônicas disponibilizadas na internet constituem um tema de grande relevância que deve ser considerado. Afinal, com o crescimento da web, não apenas tem-se permitido o acesso, produção e disseminação de informação em larga escala, por um único indivíduo ou por organizações, mas também uma revolução de toda a estrutura desta produção, disseminação e acesso que estava em vigor antes do advento da internet. Conforme apresentado anteriormente, poucos trabalhos que se dispuseram a avaliar a qualidade das informações sobre doenças, disponíveis em websites brasileiros, foram encontrados, fato este que tem implicações diretas na prática do dia-a-dia de internautas que comumente buscam informações sobre suas enfermidades, uma vez que pouco se sabe sobre a qualidade das mesmas disponibilizadas em websites brasileiros. Qual será a qualidade das informações sobre outras doenças tão importantes quanto às abordadas nos estudos revisados anteriormente que também são amplamente disponibilizadas nos websites brasileiros? Como esses websites têm descrito e abordado temas relacionados às doenças nãotransmissíveis, como, por exemplo, as patologias coronarianas, o diabetes e as doenças neurodegenerativas? $\mathrm{E}$ as doenças transmissíveis, tais como a Síndrome da Imunodeficiência Adquirida (AIDS) ou qualquer outra doença sexualmente transmissível? E as enfermidades ditas "negligenciadas", com ampla distribuição mundial, tais como a tricuríase, ascaridíase, esquistossomose, filariose, dengue, cisticercose, tuberculose e hanseníase?

Até o momento, não há como responder a todos esses questionamentos. Particularmente, no Brasil, não há uma legislação específica que trata do controle da qualidade das informações sobre saúde e/ou doença disponibilizadas na internet e/ou que estabelece critérios para a avaliação e fiscalização do que é divulgado nos websites brasileiros. Neste contexto, surge outro questionamento: quais seriam os critérios para avaliar, controlar e garantir a qualidade da informação médica divulgada na internet, a fim de que seja evitada a possível utilização de informações incorretas ou incompletas sobre várias doenças? 
Sobre este aspecto, pode-se citar o trabalho pioneiro de Sielberg et al..$^{18}$, publicado no periódico Journal of the American Medical Association (JAMA), em abril de 1997. Na ocasião, os autores registraram, conforme lembrado por Lopes ${ }^{19}$, os primeiros critérios para avaliar, controlar e garantir a qualidade das informações médicas veiculadas pela internet. Na ocasião, os autores já alertavam para as dificuldades inerentes à disseminação da informação incompleta, enganosa e sem acurácia sobre as diversas subáreas da área médica, incluindo a patologia e as doenças infecciosas, parasitárias e não-transmissíveis.

No contexto brasileiro, o que existem são esforços oriundos de órgãos institucionais, tais como o Conselho Federal de Medicina (CFM), os conselhos regionais do Rio de Janeiro e de São Paulo e a Associação Médica Brasileira (AMB), os quais procuram agir no sentido de regulamentar as informações sobre saúde e/ou doença divulgadas na internet e, dessa forma, garantir a qualidade da informação que será publicada e disponibilizada aos internautas.

Como fruto desses esforços, cita-se, como exemplo, o manual de princípios éticos para websites de Medicina e saúde na internet, instituído pelo CREMESP na resolução $n^{\circ} 097 / 2001^{20}$, o qual define princípios éticos e critérios de conduta das páginas na internet. O referido manual apresenta um conjunto de conceitos para aplicações na área de Medicina e saúde semelhantes em alguns pontos ao Health Information Technogy Institute (Hiti) e à Health on the Net (HON) Foundation, documentos estes que também estabelecem critérios para a avaliação da qualidade das informações sobre saúde. Logo em seu artigo $1^{\circ}$, o manual deixa explícito que os usuários da internet, na busca de informações, serviços ou produtos de saúde online, têm o direito de exigir das organizações e indivíduos responsáveis pelos websites transparência, honestidade, qualidade, consentimento livre e esclarecido, privacidade, ética médica, responsabilidade e procedência (Quadro 1). Esses princípios éticos são norteadores de uma política de autorregulamentação e critérios de conduta dos websites de saúde e Medicina disponíveis na internet. Em relação à qualidade, $\mathrm{o}$ manual do CREMESP dispõe o seguinte: " $A$ informação de saúde apresentada na internet deve ser exata, atualizada, de fácil entendimento, em linguagem objetiva e cientificamente fundamentada. Da mesma forma, produtos e serviços devem ser apresentados e descritos com exatidão e clarę̧a. Dicas e aconselhamentos em saúde devem ser prestados por profissionais qualificados, com base em estudos, pesquisas, protocolos, consensos e prática clínica. Os sites com objetivo educativo ou cientifico devem garantir autonomia e independência de sua política editorial e de suas práticas, sem vínculo ou interferência de eventuais patrocinadores. Deve estar visivel a data da publicação ou da revisão da informação, para que o usuário tenha certęa da atualidade do site. Os sites devem citar todas as fontes utilizadas para as informações, o critério de seleção de conteúdo e a política editorial do site, com destaque para nome e contato com os responsáveis" ${ }^{20}$.

A resolução ainda prevê que "se a ação, omissão, conduta inadequada, imperícia, negligência ou imprudência de um médico, via internet, produzir dano à vida ou agravo à saúde do indivíduo, o profissional responderá por infração ética junto ao Conselho de Medicina. São penas disciplinares aplicáveis após tramitação de processo e julgamento; advertência confidencial; censura confidencial; censura pública em publicação oficial; suspensão do exercício profissional por 30 dias e cassação do exercício profissional" 20 . Este item deixa claro certo rigor quanto à exigência do cumprimento dos princípios instituídos neste manual pelos profissionais médicos e instituições registradas no CREMESP.

Além do manual de princípios éticos do CREMESP, o Brasil ainda conta com o documento intitulado "Guia para encontrar informações seguras", originalmente de autoria da Organização Mundial da Saúde (OMS), mas que foi traduzido e adaptado para o Brasil pelo Centro de Vigilância Sanitária (CVS) do Governo do Estado de São Paulo ${ }^{21}$. O objetivo central deste documento é justamente fornecer aos usuários da internet condições de avaliação dos conteúdos de páginas a serem visitadas e usadas como fontes de informações.

\section{Considerações finais}

Conforme exposto nos itens anteriores, pode-se observar que, mesmo com a existência de documentos (não legislativos) que tratam de estabelecer diretrizes e critérios para a avaliação da qualidade das informações sobre saúde e/ou doença disponíveis na internet, grandes preocupações ainda emergem deste cenário, sobretudo, porque informações incompletas, incorretas e sem fundamentação científica ainda continuam sendo disponibilizadas nos websites brasileiros. Exemplo disso pôde ser observado nos estudos acerca da qualidade das informações sobre rinite alérgica, obesidade, leishmaniose visceral e tegumentar e sobre doença de Chagas, apresentados neste trabalho (Tabela 1). Inexatidões e omissões de informações sobre doenças podem levar a questionamentos acerca da credibilidade do conteúdo que está sendo divulgado, além de poderem confundir médicos, outros profissionais da saúde e pessoas leigas. Além disso, o paciente, que utiliza a internet para saber mais sobre a sua doença, pode entrar em desacordo com o seu médico ao se basear em informações inexatas extraídas da rede. A seguir, é apresentado um breve roteiro do que observar quando se procura informação na rede mundial de computadores sobre alguma questão de saúde e/ou doença.

Além dos critérios sumarizados no Quadro 2, os usuários da web também podem e devem utilizar os critérios de avaliação da qualidade dispostos no Manual de Princípios Éticos para Sites de Medicina e Saúde na Internet, instituído pelo CREMESP, no momento da consulta. No entanto, para que essa prática se torne uma rotina na vida do internauta, é necessário reunir esforços no sentido de estimular o uso destes documentos como ferramentas úteis para a verificação da qualidade das informações que estão sendo extraídas da internet, bem como no sentido de divulgar melhor a existência destes documentos e onde eles podem ser acessados. Tais medidas poderiam ser feitas tanto por secretarias de saúde municipais e/ou estaduais quanto por sociedades médicas e/ou outras entidades governamentais ou não.

Outra medida que poderia ser aplicada, conforme sugerida por Silva et al. ${ }^{12}$, seria a criação de portais e/ou websites dedicados exclu- 
Quadro 2: Breve roteiro para avaliação das informações sobre saúde disponibilizadas na internet

\begin{tabular}{|ll|}
\hline Critério & Descrição \\
\hline Autoria & Todo texto sobre saúde deve ter um autor responsável pela sua elaboração, e este deve estar discriminado no website. \\
Credenciais do autor & Além do nome do autor, também devem estar expressas sua formação profissional e acadêmica. \\
$\begin{array}{l}\text { Data de elaboração do texto } \\
\text { Referências }\end{array}$ & $\begin{array}{c}\text { A data em que o texto foi elaborado é essencial para o leitor verificar o grau de atualização. } \\
\text { Como em qualquer texto técnico, os autores devem informar de onde foram tiradas as informações disponibilizadas } \\
\text { pelos websites. }\end{array}$ \\
$\begin{array}{l}\text { Instituição responsável pela elabo- } \\
\text { ração do sítio }\end{array}$ & $\begin{array}{l}\text { É importante que o usuário saiba qual a instituição que divulga e chancela as informações, se tem interesse comercial } \\
\text { objetivo ou intenção da independente. }\end{array}$ \\
\hline
\end{tabular}

sivamente às questões de saúde de interesse da comunidade leiga, com informações previamente avaliadas e de fácil acesso por meio de motores de busca. Estes portais e/ou websites poderiam ser organizados pelo Ministério e Secretarias de Saúde, Conselhos de Medicina e sociedades de especialidades, que garantiriam a qualidade dos websites e das informações disponibilizadas por eles.
A disseminação correta de informações acerca dos mais variados aspectos relacionados às questões de saúde e/ou doença na internet poderá evitar problemas oriundos da obtenção, por parte dos usuários da web, de informações incorretas ou equivocadas, que podem levar, consequentemente, a prejuízos monetários e, sobretudo, danos à própria saúde da população usuária.

\section{Referências}

1. Santana S, Pereira ASD. Da atualização da internet para questões de saúde e doença em Portugal: possíveis repercussões na relação médico-doente? Acta Med Port. 2007;20:47-57.

2. Sorj B. Brasil@povo.com: a luta contra a desigualdade na sociedade da informação. Rio de Janeiro/Brasília, DF: Jorge Zahar/Unesco 2003.

3. Inteligência em Telecomunicações. (TELECO) [Internet]. Usuários de Internet no Brasil. Disponível em: http://www.teleco.com.br/internet.asp. Acesso em 11 dez. 2004

4. Bupa Helath Pulse. Disponível em: http://www.bupa.com/mediacentre/ healthpulse. Acesso em 10 fev. 2011.

5. Cuenca AMB, Tanaka ACA. Influência da internet na comunidade acadêmicocientífica da área de saúde pública. Rev Saúde Pública. 2005;39(5):840-6.

6. Castro RCF. Impacto da Internet no fluxo da comunicação científica em saúde. Rev Saúde Pública. 2006;40(N Esp):57-63.

7. Malafaia G. Análise de informações sobre a doença de Chagas disponíveis em websites brasileiros na rede mundial de computadores (internet). Arq Bras Ciên Saúde. 2009;34(3):188-95.

8. Centro de Estudos Sobre as Tecnologias da Informação e da Comunicação (CETIC br) [Internet]. TIC domicílios e usuários 2009 - área urbana. Disponível em: http:// www.cetic.br/usuarios/tic/2009/analises.htm. Acesso em 20 ago. 2010.

9. Richard JL, Schuldiner S, Jourdan N, Daurès JP, Vannerau D, Rodier M. The Internet and the diabetic foot: quality of online information in French language. Diabetes Metab. 2007:33(3):197-204.

10. Weisbord SD, Soule JB, Kimmel P. Poison on line--acute renal failure caused by oil of wormwood purchased through the Internet. N Eng J Med. 1997;337(12):825-7.

11. Hainer Ml, Tsai N, Komura ST, Chiu CL. Fatal hepatorenal failure associated with hydrazine sulfate. Ann Intern Med. 2000;133(11):877-80.
12. Silva LVER, Mello Jr F, Mion 0 . Avaliação das informações sobre rinite alérgica em sites brasileiros na rede mundial de computadores (Internet). Rev Bras Otorrinolaringol. 2005;71(5):590-7.

13. Balbani APS, Miyake MM, Mello Jr JF, Mion 0. Avaliação das Informações sobre rinite alérgica e sinusites disponíveis na rede mundial de computadores. Arq Fund Otorrinolaringol. 2000;4(3):106-12.

14. Castro FFM. Introdução. In: Castro FFM, editor. Rinite alérgica: modernas abordagens para uma clássica questão. São Paulo: Vivali, 2003; p.17-20.

15. Souza CLN, Luz ZP, Rabello A. Análise da informação sobre a leishmaniose visceral disponível em portais brasileiros da rede mundial de computadores Internet. Rev Soc Bras Med Trop. 2008;41(4):352-7.

16. Silva EV, Castro LLC, Cymrot R. Tratamento farmacológico da obesidade em páginas da Internet brasileira: análise dos Critérios Técnicos de Qualidade. Rev Ciênc Farm Básica Apl. 2008;29(2):159-65.

17. Malafaia G, Rodrigues ASL. Uma análise das informações sobre a leishmaniose tegumentar disponíveis em websites brasileiros. Saúde $\varepsilon$ Amb Rev 2009;4(1):28-35.

18. Silberg WM, Lundberg GD, Musacchio RA. Assessing, controlling, and assuring the quality of medical information on the Internet: Caveant lector et viewor--Let the reader and viewer beware. JAMA. 1997;277(15):1244-5.

19. Lopes IL. Novos paradigmas para avaliação da qualidade da informação em saúde recuperada na Web. Ci Inf. 2004;33(1):81-90.

20. Conselho Regional de Medicina do Estado de São Paulo (CREMESP) [Internet]. Guia de ética para sites de medicina e saúde na internet. Disponível em: http://www.cremesp.org.br/?siteAcao = Publicacoesfacao = detalhe s_capitulos\&cod_capitulo=26. Acesso em 11 fev. 2011.

21. Centro de Vigilância Sanitária (CVS) [Internet]. Guia para encontrar informações seguras. Disponível em: http://www.cvs.saude.sp.gov.br/ medical.htm. Acesso em 19 maio 2003. 